was a keen musician, playing the flute and several keyboard instruments.

His interest in mathematics, he tells us, was not awakened until he was 16 years of age. But after that his rise to fame was very rapid. Although his studies were interrupted by military service in the First World War, he was appointed to the Faculty at the University of Hamburg in 1923 and elected to a chair in 1926. Escaping from the tyranny of Nazi Germany, Artin emigrated to the United States in 1937. His stay in America, and especially the twelve years he spent at Princeton, had a profound effect on the development of mathematics. Many mathematicians of many nations were thus given the opportunity of benefiting from Artin's brilliance both as a research worker and as a teacher. Artin returned to Hamburg in 1958 and remaincd there until his death in 1962.

Artin will rank as one of the great mathematicians of this century. His work is admired for its depth and for its elegance, and it is distinguished by an aesthetic approach to mathematics which is communicated in lucid and eminently readable expositions, however technical their contents, and whether composed in German or in English. It was his basic conviction that "we all believe that mathematics is an art" and that "the author tries to convey the structural beauty of mathematics to his readers".

This volume is edited by Serge Lang and John T. Tate, who have prefaced the work with a short biography and an interesting discussion of some of Artin's conjectures, several of which had not been previously published. They have also added a list of text-books and lecture notes which are not included in this volume. All Artin's papers are reproduced in this collection. They are arranged according to topics, the chronological order being preserved in each section, beginning with the doctoral thesis on quadratic fields. This is followed by the section on class field theory, which includes Artin's celebrated discoveries on $\mathrm{L}$-series and the general reciprocity law. The other headings are algebraic number theory, real fields, algebra and number theory, topology, and miscellaneous, 44 titles in all. Finally, there is a set of five general papers dealing with various aspects of mathematies, historical, educational and critical, which are addressed to a wide audience. Every mathematician, whatever his field of interest, will treasure this volume, which enshrines the work of a genius whose inspiring influence will extend far beyond his own generation.

W. LEDERMANN

\section{WHITEHEAD DEFENDED}

\section{Experience and Conceptual Activity}

A Philosophical Essay based upon the Writings of A. N. Whitehead. By J. M. Burgers. Pp. vii +277 . (Cambridge, Mass.: The M.I.T. Press, 1965.) \$7.50; 57s.

THe purpose of this essay is to indicate a system of thought in which notions concerning values can find a place along with ideas of causal relationships which are applied in the physical sciences. It stems from Prof. Burgers's admiration of A. N. Whitehead, and from his belief that the views of the great philosopher deserve re-interpretation and extension because of their complexity and because Whitehead was not always the clearest of communicators. The basis of Whitehead's doctrine is that in every act occurring in the universe, experience derived from that which has gone before is integrated with conceptions concerning possibilities. To this, Burgers grafts on the theme that throughout the universe there is an underlying purpose and design and that this can be discerned in the inanimate and animate worlds; in the latter, this is reflected in conceptual activities even in the lowest animal orders. Although
Burgers recognizes the difficulty of ascribing values to any but human activity, he is "convinced that values, intentions and anticipation are not features of human life alone. I therefore believe that biological research can not come to terms with life unless it recognizes the effectiveness of such features in the activities of living organisms".

Such is the thread which winds through a book of vast scholarship supported by copious annotation. Its main defects are that argument fails to convince if premises are not acceptable-and Burgers s are founded on assumptions which are not capable of substantiation in much human experience-and that the attempt to elucidate Whitehead might have been more successful with less turgid prose, greater use of orthodox grammatical construction, and the avoidance of words whose coinage seems to have come from an overheated furnace. Inadvertently, however, the book may achieve its aim of drawing renewed attention to Whitehead's philosophy; it should lead many students to re-read his works in the original.

\section{T. H. HawkINS}

\section{DIFFRACTION AND COHERENCE}

\section{Diffraction: Coherence in Optics}

By M. Françon. Translated from the French by Barbara Jeffery. Translation edited by J. H. Sanders. (The Commonwealth and International Library of Science, Technology, Engineering and Liberal Studies.) Pp. ix +139 . (London and New York: Pergamon Press, Ltd., 1966.) 20s. net.

THIs is a book for students, bascd on the courses given by the author in the University of Paris. It contains a fairly detailed discussion of a great number of special cases of diffraction, together with an elementary discussion of coherence. Prof. Françon is known as a masterful lecturer, and it is therefore somewhat surprising that his course-book makes rather dry reading and has the character of a manual rather than a text-book. I suspect that to save space he has left out many of the illuminating remarks with which he illustrates his lectures, leaving only a skeleton of formulae. It is also somewhat surprising that in a book on diffraction phenomena which are all within the scope of Kirchhoff's integral, that general formula cannot be found and even Kirchhoff's name is not mentioned. But, lest one might accuse the author of nationalism, Fresnel zones are not mentioned either.

This makes the treatment rather too mathematical. I suspect that the beginner will have difficulties because of the reluctance of the author to introduce Dirac functions on pages 32-34, for example. Surely, it would help the beginner simply to state that the Fourier transform of an infinite sine wave is a Dirac function. It would also help him if he were to have been told, on page 51, that the Fourier transform of a periodically repeated signal goes over into a Fourier series, especially after such pains have been taken to work it out for one, two, ... repetitions. It was probably the preoccupation of the author with physiological optics which made him introduce the resolving power of an optical instrument, which after all is an objective phenomenon, as something relating to the perception by an eye with a pupil of $0.6 \mathrm{~mm}$ diameter and a contrast threshold of 0.02 . This too, I am afraid, can scarcely fail to confuse the beginner.

All this had to be said in the hope that in the next edition the author will make this a much better book, but even as it stands, it is a valuable introduction for second and third year physics students into this very important field. The many excellent illustrations make up for much that appears to be lacking in the text.

D. GaBor 